\title{
OSTEOSSÍNTESE ASSOCIADA À HOMEOPATIA NA CONSOLIDAÇÃO ÓSSEA DE FRATURA MANDIBULAR EM EQUINO
}

FREITAS, Fernanda Coutinho de ${ }^{1}$ AgOSTINHO, Juliana Maria Avanci ${ }^{2}$ MORAES , Angélica Bento Trazzi de ${ }^{3}$

BRASIL, Fabrício Bernardo de Jesus ${ }^{4}$

RESUMO: Os traumas faciais ocorrem com frequência em equinos, sendo estes ocasionados por quedas, coices, colisões e traumas; podendo resultar em até mesmo morbidade do animal. O tratamento consiste em estabilizar o foco de fratura restaurando a morfologia óssea e o alinhamento dentário, mediante à vários tipos de osteossínteses associado a terapia medicamentosa alopática e homeopática. Neste caso a terapia cirúrgica empregada apresentou um resultado satisfatório e imediato, associado à homeopatia.

Palavas-chave: Equino. Homeopatia. Osteossíntese.

\section{OSTEOSYNTHESIS ASSOCIATED TO HOMEOPATHY IN BONE CONSOLIDATION IN EQUINE MANDIBULAR FRACCTURE}

SUMMARY: The facial traumas occur frequently in horses, these being caused by falls, coices, collisions and trauma; may result in even morbidity of the animal. THE treatment is to stabilise the focus of fracture restoring bone morphology and alignment dental, through various types of osteossínteses associated with drug therapy and homeopathic allopathic. In this case the therapy surgical abigail presented a satisfactory outcome and immediate, associated with homeopathy.

Keywords: Equine. Homeopathy. Osteosynthesis.

\section{INTRODUÇÃO}

Os traumas faciais ocorrem com frequencia em equinos, devido às atividades atléticas, temperamento e condições de manejo (LOPPACHER, 1987; RAGLE, 1993; DeBOWES, 1996), ou ocasionadas por quedas, coices, colisões e traumas (HENNINGER E BEARD, 1997). Esta condição pode resultar em morbidade, devido à dor, inapetência ou à anorexia resultante do desalinhamento dentário que limita ou impede a apreensão e trituração dos alimentos (RAGLE, 1993; VALADÃO et al.,1994; CRABILL1 ; HONNAS, 2002).

\footnotetext{
${ }^{1}$ Médica Veterinária do Setor de Clínica e Cirurgia de Grandes Animais - Hospital Veterinário da Fafram

${ }^{2}$ Médica Veterinária Aprimoranda do Hospital Veterinário da Fafram

${ }^{3}$ Professora Dra. do Curso de Medicina Veterinária da Fafram

${ }^{4}$ Professor Dr. do Curso de Medicina Veterinária da Fafram
} 
O diagnóstico de fraturas odontomaxilares e mandibulares pode ser realizado somente mediante exame clínico, sendo o exame radiológico um recurso auxiliar indispensável para a avaliação precisa da extensão e natureza da fratura (RAGLES, 1993; VALADÃO et al., 1994; DeBOWES, 1996).

Vários tratamentos são preconizados nas osteossínteses odontomaxilares, como a utilização de pinos intramedulares, parafusos, talas acrílicas, placas de compressão, fixadores externo, dente outros (LOPPACHER, 1997; TREMAINE, 1998; precisa da extensão e natureza da fratura (RAGLES, 1993; VALADÃO et al., 1994; DeBOWES, 1996). Objetiva-se estabilizar o foco de fratura restaurando a morfologia óssea e o alinhamento dentário mediante um tipo de imobilização e restabelecer a função de apreensão e mastigação dos alimentos (LOPPACHER, 1997; TREMAINE, 1998).

Dentre as terapias medicamentosas não convencionais na Medicina Veterinária, a homeopatia tem se destacado, podendo até mesmo ser utilizada em associação à alopatia.

A Homeopatia (do grego Homeo $=$ Semelhante, Pathos $=$ Doença) é a ciência que trata os indivíduos doentes (e não as doenças) por meio de medicamentos preparados em diluições infinitesimais capazes de produzir em indivíduos sãos, sintomas semelhantes aos constatados nos doentes. Esta ciência baseia-se no princípio universal da Lei Natural da Cura pelos Semelhantes (SCHEMBRI, 1992).

Os princípios fundamentais da Homeopatia, reconhecidos por Hahnemann, seu preconizador, de acordo com Cavalcanti (2003) são: lei da semelhança, individualização dos sintomas e a consideração destes em sua totalidade. Para que um medicamento homeopático seja eficaz, estes princípios devem ser respeitados. Segundo o maior ou menor grau de semelhança, o resultado do tratamento será total ou nulo (SERVAIS, 2003).

A Homeopatia aplicada aos animais também aparece com Hahnemann. (BENEZ, 2002). No âmbito da Medicina Veterinária, esta ciência tem sido propagada e utilizada tanto na clínica de animais de companhia como na de grandes animais (ALVES; GOLOUBEFF, 2008).

Nesse contexto, medicamentos homeopáticos como a Arnica montana, utilizada no tratamento da dor; a Calcárea phosphorica, utilizada em afecções ósseas e dentárias; e o Pyrogenium, indicado em casos sépticos, têm ganhado força na medicina moderna (LOCKIE; GEDDES, 2001). 


\section{RELATO DE CASO}

Um garanhão da raça Quarto de Milha de 14 anos foi encaminhado para avaliação de uma fratura mandibular ocorrida há uma semana.

Ao exame clínico o animal apresentou dor à manipulação, inabilidade em fechar a boca (Figura 1 e 2), ausência de oclusão entre os incisivos superiores e inferiores, presença de alimento entre o foco de fratura e halitose fétida.

Observou-se ao exame radiográfico do ramo rostral da mandíbula uma fratura completa transversa com a presença de lesão de continuidade óssea bilateral (Figura3).

Optou-se pela correção cirúrgica da fratura após a realização da tartarectomia dos dentes incisivos inferiores e caninos. Dois parafusos corticais de $2,5 \mathrm{~mm}$ foram fixados na face lateral do ramo rostral da mandíbula, em seguida, uma cerclagem de fio de aço de 1,2 $\mathrm{mm}$ foi trançada entre os dentes adjacentes, sendo tracionada e fixada caudalmente, nos dentes caninos e nas bandas de tensão (DART; PASCOE, 1987; VALADÃO et al., 1994; TREMAINE, 1998), finalizados por uma camada de resina acrílica.

Após 3 dias da osteossíntese observou-se instabilidade do parafuso direito, drenando secreção purulenta. Ambos os parafusos foram removidos após a avaliação radiográfica que evidenciou área de lise óssea.

No pós-operatório imediato o animal foi medicado com morfina $(0,2 \mathrm{mg} / \mathrm{kg}$, BID, por 2 dias); flunixin meglumine $(1,1 \mathrm{mg} / \mathrm{kg}$, SID, por 5 dias $)$; ranitidina $(2 \mathrm{mg} / \mathrm{kg}$, TID, por 10 dias); ceftioufur (2mg kg, SID, por 25 dias); Arnica montana $6 \mathrm{CH}$ (5 glóbulos, QID, por 30 dias); Calcárea phosphorica, 6CH (5 gotas, QID, por 30 dias), Pyrogenium 6CH (5 gotas, QID, por 25 dias) e higienização da boca realizada 2x ao dia com solução fisiológica e Iodo Povidine Tópico a 10\%, após a remoção de todo alimento.

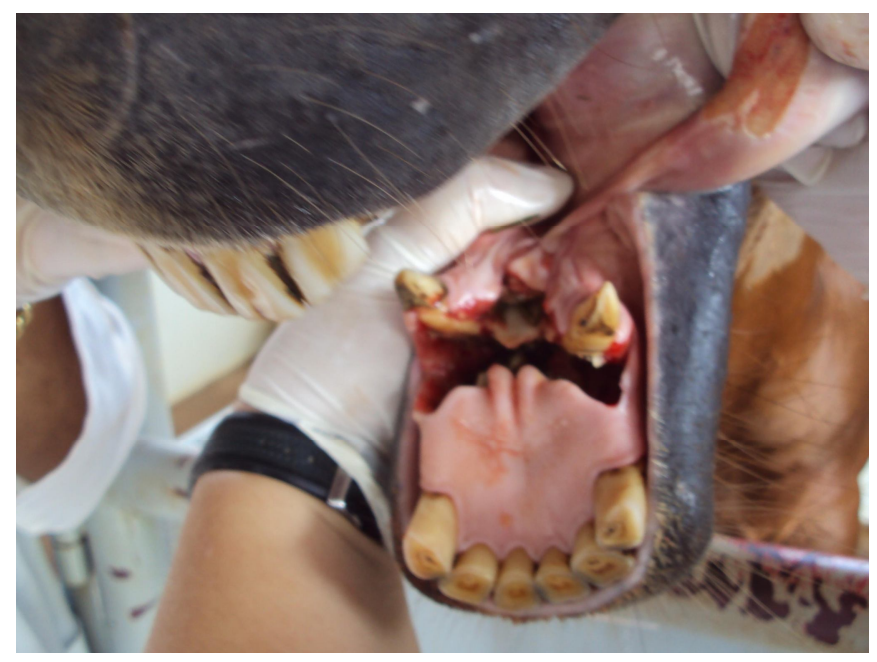

Figura 1- Presença de uma fratura completa transversa no ramo rostral da mandíbula. 


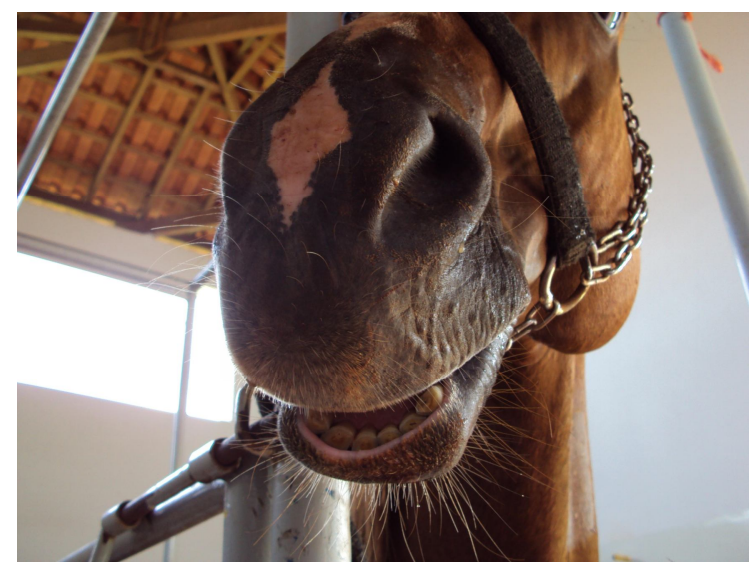

Figura 2- Imagem fotográfica demonstrando a inabilidade de fechar a boca, evidenciada pela distância apresentada entre o lábio inferior e superior do animal.

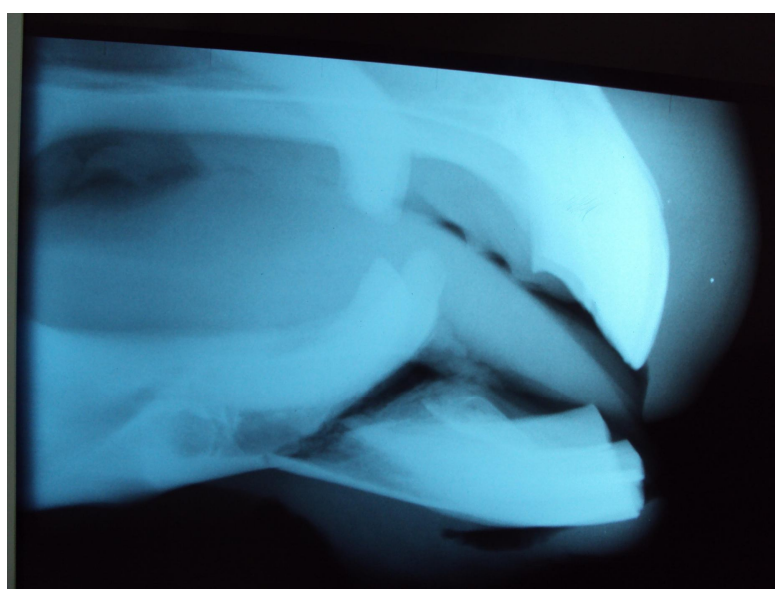

Figura 3- Imagem radiográfica do ramo rostral da mandíbula apresentando uma fratura completa transversa com a presença de lesão de continuidade óssea bilateral.

\section{RESULTADOS E DISCUSSÃO}

Com um dia de procedimento cirúrgico o foco de fratura apresentava-se estável, permitindo ao animal apreender e mastigar normalmente.

O parafuso cortical como apoio caudal da banda de tensão foi inserido conforme preconizado por Loppacher (1987), mas os parafusos foram removidos em virtude da infecção instalada. No entanto, não ocorreu o afrouxamento da cerclagem, sendo associado à utilização da resina acrílica que auxiliou na manutenção da fratura já reduzida concordando com o relato de Alves et al. (2008).

A técnica cirúrgica associada à terapêutica empregada representa um modelo viável de tratamento em virtude dos bons resultados obtidos e pelo baixo custo, ressaltando-se aí o uso da homeopatia. Este método de tratamento reflete em inúmeros benefícios incluindo seu 
baixo custo, isenção de efeitos colaterais ou reações adversas, fácil forma de administração e a possibilidade de ser associada à alopatia.

No presente relato, pôde-se verificar grande contribuição no tratamento da dor com o uso de Arnica montana, observação também feita por Jeffrey ; Belcher (2002). A reparação óssea pode ter sido acelerada pelo uso de Calcárea phosphorica, concordando com Werkman (2009) que verificou maior eficiência desse medicamento nas fases iniciais do processo de consolidação. Por fim, o uso do Pyrogênio para tratamento da osteomielite encontrada, pode ter proporcionado grande sucesso, considerações estas também feitas por Lockei ; Geddes (2001).

\section{CONCLUSÃO}

Os sinais clínicos de preensão, mastigação e ingestão de alimento foram úteis na avaliação imediata da técnica empregada neste relato, apresentando um resultado satisfatório e imediato.

Neste caso obteve-se êxito no tratamento tradicional associado à homeopatia.

\section{REFERÊNCIAS}

ALVES, G.E.S. et al. R. Fraturas odontomaxilares e mandibulares em eqüídeos tratados por diferentes técnicas de osteossíntese. Arq. Bras. Med. Vet. Zootec. v.60, n.6, p.1382-1387, 2008.

ALLEN, H.C. Sintomas-chaves da matéria médica homeopática. São Paulo: Dynamis, 1996 .

ALVES, A. A.; GOLOUBEFF, B. Avaliação de medicamento homeopático comercial sobre a composição físico-química e a contagem de células somáticas de leite cru em uma propriedade leiteira. 2008. Monografia (Especialização em Homeopatia Veterinária) Instituto Homeopático Jacqueline Peker.

BENEZ, S. M. Manual de homeopatia veterinária: indicações clínicas e patológicas. São Paulo: Robe, 2002, 594 p.

BOERICKE,W. Manual de matéria médica homeopática: sintomas-chaves e características dos principais medicamentos (clínicos e patogenéticos). São Paulo: Robe, 1997. 430 p.

CAVALCANTI, A. M. S. Introdução à homeopatia. Niterói: Instituto de Saúde Comunidade da Universidade Federal Fluminense, 2003. 83 p. (Apostila). Disponível em: <http://www.uff.br/ses/graduacao/Apostila.2003.doc>. Acesso em: 12 jul. 200 
CRABILL, H.R.; HONNAS, C. Mandibular and maxillary fracture osteosyntesis. In:

BAKER, G.J.; EASLEY, J. (Ed). Equine dentisty. London: Saunders, 2002. p.259-270.

DART, A.J.; PASCOE, R.R. Treatment of a bilateral mandibular fracture in a mare using an intraoral acrylic splint. Aust. Vet. J., v.64, p.382-384, 1987.

JEFFREY, S. L.; BELCHER, H. J. Use of arnica to relieve pain after carpal-tunnel release surgery. Altern. Ther. Health Med., v.8, p.66-68, 2002.

HENNINGER, R.W; BEARD. WARD. Rostral Mandibular and Maxillary Fractures: Repair by interdental Wiring. AAEP Proceedings... v. 43, p. 136-137, 1997

LOCKIE, Andrew; GEDDES, Nicola. Guia completo de homeopatia: princípios e métodos de tratamento. Tradução: Jussara Simões. São Paulo: Ática, 2001. 240p.

RAGLE, C.A. Head trauma. Vet. Clin. N. Am.: Equine Pract., v.9, p.171-183, 1993.

SCHEMBRI, J. Conheça a homeopatia. 3.ed. Belo Horizonte: Rona, 1992. 268 p.

SERVAIS, P. Larousse da Homeopatia. Larousse, 2003. 318p.

TREMAINE, W.H. Management of equine mandibular injuries. Equine Vet. Educ., v.10, p.146-154, 1998.

VALADÃO, C.A.A.; MARQUES, J.A.; PADILHA FILHO, J.G. et al. Uso de cerclagem e resina acrílica em fraturas mandibulares dos eqüideos. Cienc. Rural, v.24, p.323-327, 1994.

WERKMAN, Cristina. Estudo dos efeitos risedronato e da calcarea phosphorica $6 \mathrm{ch}$ na reparação óssea ratos machos castrados. Tese de Mestrado: Programas de Pós-Graduação da CAPES, 2009. 